\title{
Responsabilidad social de un estudio de abogados especializado en materia penal
}

\author{
ROGER YON*
}

\author{
A mi padre Linán, quien señala persistentemente \\ que el ejercicio del Derecho penal \\ no tiene por qué ser indigno.
}

\begin{abstract}
SUMARIO: I. INTRODUCCIÓN.- II. RESPONSABILIDAD SOCIAL.- III. CASO REAL.- IV. LAS INSTITUCIONES.- V. LA CORRUPCIÓN Y LOS ABOGADOS.VI. LOS ABOGADOS.- VII. LAS UNIVERSIDADES.- VIII. LOS PROCURADORES.IX. LOS PRACTICANTES.- X. CONCLUSIÓN.
\end{abstract}

\section{INTRODUCCIÓN}

Desde luego que la visión que se brindará al lector tiene un contenido subjetivo y valorativo, toda vez que no es posible brindar una visión social neutral o avalorada de la realidad ${ }^{1}$. A pesar de la carga subjetiva, resulta necesario que el lector encuentre en blanco y negro lo que aparece como «el estado de las cosas», sobre todo si está —o puede estarconectado con el aparato de justicia. Lo que a continuación se presenta es lo que todo el mundo conoce y comenta, pero nada más. ¿Qué se

* Es abogado y profesor principal de la Facultad de Derecho de la Pontificia Universidad Católica del Perú.

1 El profesor Silva Sánchez ha destacado que «[...] hay que suponer que JAKOBS [sic] acepte, sin embargo, al menos, un límite ontológico: a saber, el que viene dado por el fenómeno (ciertamente correspondiente a la ontología) de la circularidad hermenéutica de los procesos de conocimientos humanos ( $\mathrm{y}$, por añadidura, científicos). Esto es, en otras palabras, el que se manifiesta en la fuerza de las precomprensiones del científico social (y no sólo del social) cuando éste procede a formular enunciados sobre la realidad. Ello implicaría que cuando JAKOBS (en su reivindicada condición de 'mensajero' de la autocomprensión de una determinada sociedad) formula una determinada regla de imputación se encuentra en ello también subjetivamente condicionado por sus propios prejuicios acerca de aquella autocomprensión social. Por tanto, contra lo que quizás pueda desprenderse de algunos de sus textos, su teoría de la imputación no sería capaz de expresar una fenomenología objetiva y pura de la constitución (autocomprensión) de una sociedad dada, sino que se vería indefectiblemente lastrada por el subjetivismo epistemológico que a todos nos condiciona». SILVA SÁNCHEZ, Jesús María. «Política criminal en la dogmática: algunas cuestiones sobre su contenido y límites». En Política criminal y nuevo Derecho penal. Libro homenaje a Claux Roxin. Barcelona: José María Bosch Editor, 1997, p. 24. El mismo autor opina que «la llamada ciencia del derecho penal es así mismo un agente político-criminal. En efecto, en la actualidad es compartido de modo general el juicio acerca de la ausencia de neutralidad valorativa de la dogmática y de la ciencia de la legislación penal». En Tiempos de Derecho Penal. Montevideo/ Buenos Aires: Editorial IB de F., 2009 , pp. 15 y 16. En la misma línea, con una perspectiva relacionada a la interpretación de la ley, el profesor Balcarce sostiene que «en nuestro país, debido a la ingenuidad de muchos $-\mathrm{y}$ a la intencionalidad de pocos [...] — pretendió hacer creer que la interpretación de la ley era una actividad despojada de toda ideología; que existía una única, posible e inopinable intelección de las reglas jurídicas y, por último, que la actividad que desempeñaba el intérprete, lejos de ser una actividad argumentativa, sometida a crítica y consenso, era una actividad lógico-formal. Luego, pues, muy corta distancia existía entre estas creencias y considerar ciertos libros como 'biblias interpretativas', lugares únicos en donde se debía abrevar el intérprete para saber lo que decía la ley. Eficiente política científica para fomentar la fama personal de algunos autores, pero gravemente perjudicial para la evolución de la ciencia. Con esto sí existía seguridad jurídica, pero solamente para quien había logrado imponer (subrepticiamente) su propia ideología». BALCARCE, Fabián I. Antijuridicidad penal. Principios generales. Córdoba: Editorial Mediterránea, 2001, p. 90. 
pretende al escribir lo que ya todos saben? Tal vez, además de alcanzar que cuatro personas penetren en el contenido de este artículo, que se denuncie lo que pasa en el sistema de justicia, anhelando que tales denuncias despierten la conciencia social de que, entre las muchas urgencias por atender (discriminación, pobreza, inseguridad ciudadana, baja calidad en la educación, insultante desigualdad social, etcétera), esta, la de la justicia, no puede esperar más. Claro que no faltarán los pesimistas que señalen que las cosas no cambiarán, o los cínicos corruptos que se «acomoden» a la situación para decir con voz adusta que «es urgente una reforma» —en clara alusión a una nueva de las tantas que ya se hicieron y no reformaron nada ${ }^{2}$. Ya se sabe que con estas personas no se puede contar para construir un sistema real de justicia.

\section{RESPONSABILIDAD SOCIAL}

Si uno se pregunta si los estudios de abogados deben asumir una responsabilidad social traducida en casos sociales (pro bono), de repente la respuesta desemboque en apreciaciones parciales que no permitan dar cuenta real de tal responsabilidad y se correría el riesgo de caer en un diseño muy bien coloreado pero que puede esconder peligrosamente una práctica del ejercicio profesional que, detrás de ese maquillaje, atente de manera sistemática contra las instituciones de justicia.

No es que el pro bono sea cuestionable en sí mismo. Asumir la defensa de una causa justa que no cuenta con los recursos económicos para contratar abogados eficientes forma parte de la esencia misma de nuestra profesión. El cuestionamiento surge cuando dichos casos son utilizados de manera instrumental para esconder una determinada práctica profesional, contraria, justamente, a la esencia de la responsabilidad social, y se olvida que la asunción del pro bono debiera ser parte del porqué se es abogado.

\section{CASO REAL}

Lo esencial es que el ejercicio profesional, más allá de asumir casos sociales, se traduzca en la aplicación de principios y valores a la totalidad del litigio. Un caso real resulta ilustrativo. Eran mediados de los años ochenta y, ante la desesperación de los pasos elefantiásicos de la justicia penal

2 Benavides Piaggio resalta, con ocasión de las elecciones que se avecinan (municipales, regionales y posteriormente presidenciales), interesantes comentarios al respecto que refuerzan lo señalado: «cómo pudieran haber postulantes con otras características, en una sociedad deshilvanada, escasamente solidaria en la que los vecinos de distritos limeños se movilizan para impedir que se construya en sus inmediaciones un hospital para niños pobres y, en el otro lado del espectro social, cientos de miles de compatriotas que habitan en cerros miserables, donde lo más reluciente - por el intenso color de la pintura - es el apellido de quien nos deshonró como nadie [...] de cara a los próximos comicios percibimos una sensación de fealdad, proveniente de la gran desproporción entre la forma y la función de los liderazgos, que refleja la fragmentación y la ausencia de una auténtica preocupación por lo circundante [...] recordemos que el genio de la Lampedusa mostró nítidamente, en 'El Gatopardo', las sombrías consecuencias de acciones enredosas y pomposas ceremonias, que sugieren transformaciones radicales, cuya finalidad es lograr que nada cambie». BENAVIDES PIAGGIO, Carolina. «Nexos voluntarios: 'El candidato ideal'». Diario El Comercio, A5, miércoles 3 de febrero de 2010, Lima. 
y del grado de corrupción ${ }^{3}$ y compadrazgo que se vivía en el «Palacio de la (in) Justicia», un abogado recientemente graduado le preguntaba a otro de mayor experiencia en el litigio qué había que hacer para alcanzar justicia. «iAcaso quemar el expediente?». A lo que el otro le respondió: «No, sigue luchando y busca en lo académico nuevas formas imaginativas de defensa». Aquella respuesta marcó el derrotero de ese joven profesional, puesto que, sin trampa, ni compadrazgo, ni corrupción, debía luchar con todas las fuerzas y alcanzar una resolución judicial justa en un caso evaluado previamente.

Le tocó al joven abogado entonces el caso de una compañía de seguridad que aducía haber sido víctima de un ataque senderista, producto del cual había muerto un miembro subversivo. Se concurrió a verificar el hecho de la supuesta legítima defensa y semanas después se descubrió que todo era un montaje para proteger a uno de los miembros de esta empresa de seguridad, quien había matado fríamente a un borrachito por haberlo llamado «negro», a lo cual el guardia de seguridad había respondido con dos certeros balazos en el corazón. Cuando se descubrió el montaje, y a pesar de que el miembro de seguridad — por trámites judiciales ya iniciados - podría alcanzar su libertad pronto, el joven abogado dejó el caso. Dos años después, al encontrar a la madre del guardia de seguridad en los pasadizos del Poder Judicial, esta le confesó que no estaba allí por aquel caso, sino por uno nuevo: su hijo había vuelto a matar. ¿Cómo carga el abogado con ese muerto? El joven abogado ratificó entonces las palabras del abogado de mayor experiencia.

Es válida la pregunta respecto de qué hubiera pasado si aquel abogado experimentado, en lugar de inducirlo a estudiar más el caso y recurrir al aspecto académico para contar con apoyo dogmático para resolverlo, hubiera fomentado en el novel abogado el facilismo para resolver el caso con el compadrazgo - hoy en día sería: «Te consigo una beca para un curso del Nuevo Código Procesal Penal», «Te puedo ayudar a buscar trabajo» $\mathrm{O}$ «Te ayudo en tu postulación a la función pública»— o simplemente lo hubiera instigado a «comprar» una resolución favorable.

\section{LAS INSTITUCIONES}

Ahora bien, debemos preguntarnos qué está pasando en las instituciones públicas y, específicamente, en el sistema de justicia. Porque si nos preguntamos cuál es la responsabilidad social del abogado o de un estudio

3 Rafo León, en el prólogo del libro de la doctora en Antropología, Liuba Kogan, grafica el asentamiento de la corrupción como parte de la historia misma del país: «junto con la corrupción, la falta de carreteras, los accidentes geográficos tan marcados y el cau cau, los científicos sociales componen el cuadro de los peores males que tienen que soportar el Perú, desde siempre. Vivimos en un país que no es tal, ya lo dijo Basadre con más claridad y elegancia: 'seres desconcertados', y ahí queda. Rupturas, desencuentros, prejuicios y diferencias abismales en todo orden de cosas nos han hecho lo que hoy somos, un escenario de batalla cotidiano donde todo el mundo odia a todo el mundo, la desconfianza es la norma y la forma de manejar auto, el modelo». En KogAN, Liuba. Regias y conservadores. Mujeres y hombres de clase alta en la Lima de los noventa. Lima: Fondo Editorial del Congreso del Perú, 2009, p. XI. 
de abogados, resulta necesario antes $-\mathrm{o}$ con ello- conocer el espacio en el cual se van a desplegar actividades que puedan ser atribuidas a una responsabilidad social. En el panorama social, hay candidatos a alcaldías, al Congreso, etcétera, con antecedentes y procesos penales abiertos por delitos de corrupción, peculado, entre otros. Sin embargo, se trata justamente de los candidatos que lideran las encuestas, y es muy probable que sean elegidos. ¿Piensa acaso el ciudadano que dicho candidato, si mantuvo una conducta inmoral al ser profesional o empresario, e incluso cuando en algunos casos fue filmado recibiendo dinero en contraprestación de la venta de su conciencia cuando «hacía empresa», luego, cuando se dedique a la función pública, no va a tener el mismo modus operandi que ha «practicado» siempre? iO es que nos da lo mismo la forma en que se desempeñe la función pública y, por toda reacción, nos resignamos a señalar: «Así ha sido siempre, así es y lo que nos queda por hacer es reacomodarnos en ese ámbito»? Con ese «proyecto personal» caminamos inertemente hacia el futuro.

Tan indiferente nos resulta la corrupción y la progresión de los delitos - la «única propuesta de solución», en materia penal, ha sido y es sobrecriminalizar las conductas y aumentar las penas- que no es casualidad que, a media cuadra de la sede del Poder Judicial, se encuentre el mayor centro de falsificación de todo el país, que opera con sentida impunidad: Azángaro. Cierto es que de vez en cuando las «batidas» ahuyentan a los falsificadores, pero, terminadas estas, aquellos vuelven a instalarse y a ofrecer desde carnés de medio pasaje hasta pasaportes de la comunidad europea, pasando por títulos profesionales.

Algunas encuestas señalan que a más del cincuenta por ciento de los peruanos le es indiferente la corrupción, que a la gran mayoría le interesa el estado de la producción legislativa o de resolución de causas judiciales solo como desahogo «chismográfico» de su constante frustración personal, laboral o familiar. Aquí la Iglesia pareciera haber perdido presencia porque, de ponerse las pilas, podría llenar el vacío de valores con actividades de proyección social que estimulen la participación ciudadana, siempre desde una perspectiva crítica, actual, que vincule al ciudadano de a pie y sus aflicciones con los proyectos políticos, al proponer - mediante una convocatoria abierta - que el ciudadano se comprometa con su realidad, que deje de lado postulados principistas abstractos como fórmula de resolución de conflictos sociales o particulares, los cuales ignoran el problema en concreto para recurrir a soluciones - muchas veces - contrarias a tales principios abstractos.

Así, la indiferencia puede conducirnos a la aceptación de aterradoras consecuencias:

- Debe amarse al prójimo como a sí mismo (principio abstracto).

- No se tiene dinero o este no alcanza para mantener satisfactoriamente a la familia (problema concreto). 
- Se secuestra a una persona con solvencia patrimonial para extorsionar económicamente a su familia y así superar los problemas económicos que aquejan (solución al problema concreto).

De ahí la importancia de que las instituciones de justicia, los centros de formación universitaria y los estudios de abogados asuman la responsabilidad social que les toca respecto de la formación de los nuevos abogados, no solo en el ámbito académico, sino especialmente en el ejercicio profesional. Debe así entonces promoverse en la formación de los jóvenes abogados una constante preocupación por el estado de las instituciones y, en específico, de los aparatos de justicia, evitando toda indiferencia - más grave aún cuando se trata de un profesional del Derecho—, que no genera más que impunidad. Y más aún si se tiene en cuenta que, para ejercer, el abogado litigante debe aprender a desenvolverse al interior de estas instituciones.

\section{LA CORRUPCIÓN Y LOS ABOGADOS}

Existen situaciones atávicas que propician la corrupción o que constituyen elementos criminógenos para que esta se produzca. La Policía Nacional del Perú es la encargada de investigar los delitos y de producir un informe que conlleva valoraciones jurídico-penales y en el que se adopta una posición «jurídica» respecto del investigado. Al contar con dicha «posibilidad», no es difícil hallar policías que puedan estar a la expectativa del ofrecimiento del «simpático y popular doctor Chantada», más aún si se tiene en cuenta las condiciones en las que los miembros de esta institución prestan servicio y se enfrentan a la criminalidad clásica:

- sueldos que no alcanzan para cubrir las necesidades mínimas, turnos de trabajo que oscilan «entre lo administrativo y lo marcial»y que alcanzan las 24 horas;

- necesidad de trabajar uniformados en vigilancia de supermercados, bancos, etcétera, para llevar algo más a la canasta familiar;

- destaques a zonas remotas sin tener en cuenta estudios o esfuerzos académicos del personal; además de

- frustración al no contar con los mínimos recursos para trabajar (son los propios policías quienes tienen que encargarse de proveerse los materiales de trabajo y quienes deben asumir el costo del traslado a otras zonas de servicio, la compra de las municiones y, para remate, el pago de un seguro de vida que les descuentan del sueldo, el cual ni alcanza para cubrir el sepelio $\left.{ }^{4}\right)$.

¿Qué hacer, entonces, con la policía? Cierto es que el Nuevo Código Procesal Penal les restringe actuación, con lo que es de pensarse que,

RESPONSABILIDAD SOCIAL DE UN ESTUDIO DE ABOGADOS ESPECIALIZADO EN MATERIA PENAL 
con la aplicación de esta nueva normativa, la demanda de policías corruptos podría descender. Sin embargo, debe dudarse que este descenso sea permanente, puesto que la necesidad y la situación precaria subsisten. Entonces, será mejor para la seguridad ciudadana que se exija a la Policía Nacional del Perú, bajo sanción incluso penal, una actuación transparente, ipero de la mano de sueldos y condiciones dignas!

Y que no se diga que no hay presupuesto para ello. Basta preguntarse ¿dónde está todo el dinero incautado a la mafia de la corrupción?; ide dónde salen los bonos extraordinarios y aumentos a funcionarios públicos y políticos que se pasean a diario por el Congreso - a quienes, criollamente, se les identifica como «come pollo», «roba luz», «colocador de parientes», etcétera—? La salida más ponderable a esta situación estructural es un replanteamiento de todo el sistema de remuneraciones y condiciones laborales de la Policía, y no actos reformistas que se levantan en la coyuntura de un año electoral ${ }^{5}$.

En cuanto a instituciones como el Ministerio Público y el Poder Judicial, la provisionalidad y la falta de formación en el servicio público generan que en muchos casos se encuentren operadores dispuestos a exponer sus resoluciones «conforme al cristal con que se les mire». Dicha problemática es propicia para el aprovechamiento de determinados abogados y estudios de abogados. Así, los abogados en litigio que han trabajado en la Fiscalía o en el Poder Judicial exponen su carta de presentación ante el cliente expresiones como las siguientes: «Ese fiscal es mi pata», «El fin de semana salgo a tomar con el juez» $\mathrm{O}$ «Uy, no sabes cómo nos juergueamos con el asistente de la Corte Suprema». O, con mayor sutileza, algún abogado resulta ser «el maestro» del juez o del fiscal. Ante ello, las partes litigantes, en lugar de contar con argumentos jurídicos, poseen por abogado al «amigo» del juez, al «compadre» del fiscal o al «compañero de juerga» de ambos.

Instituciones como estas, si quieren mejorar la calidad de sus operadores, deberían concentrar esfuerzos en su formación. Pero no con cursos que en cuatro meses pretenden cubrir toda la materia penal general, penal especial, penal constitucional, penal económica, procesal penal, procesal constitucional, etcétera, con lo cual la formación es más bien un mero aglutinamiento de información que no cuenta con el apoyo de metodología educativa alguna, en la que «pasar el curso» cubre toda aspiración. Por lo tanto, ambas instituciones debieran destinar un presupuesto significativo para la formación y la actualización de sus operadores. Es harto conocido que importantes universidades de Europa - por citar dos: Salamanca y Castilla La Mancha, ambas en España— cuentan con la mayor disposición para recibir fiscales y jueces en ejercicio y capacitarlos mediante cursos de actualización que les permitan contar con el soporte académico que tanto necesitan.

5 El Diario El Comercio del día sábado 4 de febrero de 2010, en su sección A2, ha destacado los reclamos y la complejidad del otorgamiento de los bonos para policías y militares. 
Un dato peculiar: los operadores del Ministerio Público y del Poder Judicial no solamente revelan lenguaje y costumbres comunes, propios del sistema legal en el que desarrollan sus actividades, sino que compartir estas características en muchos casos los conducen hasta el matrimonio. No es raro encontrar que un juez o un fiscal estén casados con otra persona vinculada al Poder Judicial o al Ministerio Público, como si los funcionarios tuvieran una suerte de comunidad particular en donde el ciudadano es un extraño.

Ahora bien, debe quedar claro que un fiscal o un juez sin formación ${ }^{6}$ son más proclives a resolver un caso por intuición y por amistad que por conocimientos asentados en la dogmática ${ }^{7}$ o por el soporte académico y la experiencia con que el ciudadano de a pie espera que su conflicto sea resuelto. Operadores con tal «deformación», a cambio de una ventaja económica, definitivamente emitirán cualquier resolución.

\section{LOS ABOGADOS}

En cuanto a los abogados, podemos encontrar desde aquellos que venden sus firmas «a sol» en la puerta lateral del «Palacio de la (in) Justicia», hasta aquellos que, habiendo sido secretarios de juzgado u operadores de la fiscalía, se reúnen con secretarios y jueces en bares o en campeonatos de fulbito para «conectarse» con nuevos casos. Se podría decir que estos son los menos lesivos al sistema.

Existen más bien dos grandes grupos de abogados que sí corroen el sistema y no solo se aprovechan de la anteriormente descrita «desgracia» de nuestras instituciones públicas, sino que la promuevan y la mantienen, toda vez que es instrumental a sus intereses. En primer lugar, está el sector de abogados que han encontrado en el término «eficacia» la materialización de presentar al culpable como inocente bajo el rótulo de «No importa cómo, tú me sacas del caso o lo ganas», aun cuando se pretenda dar la espalda a la verdad sobre cómo acontecieron los hechos y sin importar si el cliente es inocente o no. Se trata de litigantes que se venden como dispuestos a todo.

En segundo lugar, existe un grupo de abogados que se esconde en el discurso académico y nunca se «ensucia las manos», pues dispone de otros colegas que lo hacen por ellos. Asumen grandes casos de compañías y/o

6 Silva destaca, en relación con la labor del juez, que «la legalidad penal requiere de él una vinculación a la letra de la ley, así como una adecuación a los cánones axiológicos constitucionales, aspectos clave en la legitimación democrática de las sentencias. Pero también una adecuación a los métodos de interpretación y aplicación propios de la ciencia jurídica, que también contribuyen a la estabilidad aplicativa». SILVA SÁNCHEZ. Tiempos de Derecho Penal. Óp. cit., p. 23.

7 De nuevo, Silva Sánchez señala que «La subsistencia de la dogmática, sin embargo, se haya íntimamente asociada a la concepción de ésta como una disciplina que tiene que ver con la construcción, reconstrucción y sistematización de reglas para llevar a cabo una imputación de responsabilidad penal, conforme a Derecho, segura e igualitaria. De modo que ha de quedar claro que un determinado ordenamiento jurídico-penal nacional, positivo, no constituye el objeto de la dogmática de la teoría del delito, sino sólo el límite de su construcción de lege lata [sic]». Ibíd., pp. 28 y 29.

RESPONSABILI-

DAD SOCIAL DE

UN ESTUDIO DE

ABOGADOS ES-

PECIALIZADO EN

MATERIA PENAL 
personas que pertenecen a los sectores $\mathrm{A}$ y $\mathrm{B},{ }^{8}$ que, por el apremio de salir del caso o porque realmente son culpables, quieren invertir en cambiar el sentido de las resoluciones y de la realidad. No solamente corrompen a jueces y funcionarios, sino que además están vinculados con las universidades y se hacen pasar por académicos y destacados profesores. Utilizan el aspecto académico para «lavarse la cara», confundir y, al mismo tiempo, lanzar el mensaje publicitario: «Te soluciono el problema». Y lo solucionan vendiendo la imagen de que su cliente - la empresa - es cuasi inocente o víctima, acompañado de resaltar que cuenta con una «defensa de prestigio».

No faltan algunos abogaditos que fueron consultados en la radio acerca del caso Fujimori y que ya durante el proceso comentaban que «tenía grandes deficiencias procesales y que podía terminar en una absolución o en una condena»; ellos generaban incertidumbre y sembraban la idea de que la absolución o la condena podrían suceder dada una decisión estrictamente subjetiva. Esos abogados, luego de emitida la sentencia condenatoria, tuvieron el atrevimiento de señalar que dicha sentencia -que ya quisiera cualquier abogado, para su caso, haber obtenido por el exhaustivo nivel de análisis, contenido y detalle del proceso- podría ser materia de un hábeas corpus, al aducir, sin detallar, la existencia de deficiencias en la valoración de la prueba indiciaria o al cuestionar la teoría de Roxin, que ha servido para condenar a criminales de lesa humanidad y corruptos que lideraron aparatos organizados de poder en otros países.

A propósito, cabe puntualizar el caso de un libro que ha llegado mediante el servicio de correos a distintos estudios de abogados: El caso de la familia Chacón de Vettori. Cómo no debe realizarse un proceso penal. Lo primero que llama la atención sobre este es que, tratándose de alegatos de la posición jurídica de una causa judicial, no aparezcan los nombres de los abogados que han participado en su asesoría y redacción. ¿Por qué el anonimato, por qué esconderse en la sombra? Si sus argumentos jurídicos son válidos, ipor qué no decirlo a través de las personas que han redactado esta publicación, compuesta por meros alegatos legalistas? Pues se recurre a muchos autores, aunque sin coherencia argumentativa, y muchas veces se descontextualizan las citas. De ese modo, se hubiera podido conocer de quién proceden y nos orientaría respecto del

$8 \mathrm{Al}$ respecto, véase el importante y ya citado estudio de Liuba Kogan, especialmente su introducción («Los estudios sobre sectores altos; las relaciones de género y los sectores altos en la Lima de los 90; las nuevas elites en la era de la globalización») y el capítulo primero («Mujeres y hombres: ¿iguales o diferentes?»). En la introducción, explica cómo y por qué se formaron familias ricas en el Perú, a la par que, en el primer capítulo, da cuenta del tratamiento que han merecido los géneros y los estudios que se han realizado sobre sexualidad y género, esto último circunscrito a la ciudad de Lima. En KogAN, Liuba. Regias y conservadores. Óp. cit.

9 Este camuflaje también le sirve a un sector para ostentar cargos de asesores en el Congreso, en comisiones revisoras, T.C., etcétera. Sería lamentable que también estén «asesorando" al Consejo Nacional de la Magistratura en la selección y el nombramiento de jueces y fiscales. Definitivamente, ello resulta una estocada mortal para la selección de jueces y fiscales idóneos. Otro sector, de mayor peso y experiencia en actos corruptos, no necesita salir del anonimato, puesto que recurre al "cobro de favores" para que sus postulantes preferidos accedan al puesto o al ascenso. Los sectores políticos también participan presionando para que se seleccione a su candidato. 
respaldo académico del autor (real) de las anotaciones penales, lo que con las omisiones señaladas (autor y editorial anónimos) no es posible, a pesar de mencionarse nombres de académicos nacionales y extranjeros (Roxin, Zaffaroni, Jescheck, López Pelegrin, entre otros), de cuyo «apoyo» a la posición del general es imperativo dudar.

Estas insalvables omisiones no fomentan la discusión jurídica de cara a alcanzar un respaldo o un rechazo mediante una crítica alturada. De ahí que se entienda menos por qué los autores de esta publicación no salen al frente para dar a conocer quiénes son y cuál es el soporte jurídico de la defensa del general Chacón, si es que se pretende defender su posición. La publicación remitida con una carta presuntamente firmada de puño y letra por el general Walter Chacón Málaga y por su esposa, Aurora de Vettori de Chacón, adolece de serias faltas ortográficas que hacen dudar que sea de su autoría, ello sumado a que, a diferencia de la carta, se recurre a un lenguaje propio de una persona que se dedica al litigio y que ninguno de ambos ostenta.

Ni siquiera los defensores de un ex presidente condenado por delitos de lesa humanidad recurrieron a esconderse, a pesar de los graves cargos por los que se le condenó. Ahora bien, nos cuestionamos si lo mejor para nuestra profesión es reemplazar los argumentos jurídicos y la verdad por posiciones meramente mediáticas o políticas.

\section{LAS UNIVERSIDADES}

No cabe duda de que los grupos de abogados antes mencionados sí corroen el sistema y las instituciones. De inmediato se levanta la interrogante de si las universidades deben permitir aquello que, para los políticos, resulta ser sumamente fácil: desdoblarse. Es decir: «Hablo como persona, no como político» $\mathrm{O}$ «Hablo a título personal, no en representación de mi bancada o partido». Y que, en el caso de estos abogados, sería: «Una cosa es lo que digo en la universidad, y otra lo que hago y digo con ocasión de litigar». Pretenden entonces soslayar en la universidad la forma cómo trabajan y sus métodos para otorgarle apariencia de inocente al culpable en casos que asumieron afirmando que «todos tienen derecho a una defensa».

Ahora bien, felizmente para el sistema de justicia y para la universidad, existen los San Martín, los Prado Saldarriaga, los Príncipe Trujillo, los Guillén o los que, como operadores anónimos, son la excepción a este entramado y complejo mundo judicial y fiscal. Cabe destacar a aquellos que de su paupérrimo sueldo toman dinero para comprar libros y publicaciones académicas, que participan en cursos de actualización y que siguen siendo pobres pero que dignifican su rol de operadores de justicia.

La universidad no solo debe centrar su punto de formación en la cantidad de información que pueda otorgar al abogado, sino fijar su mirada en

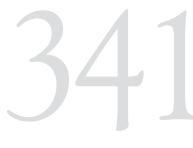

RESPONSABILI-

DAD SOCIAL DE

UN ESTUDIO DE

ABOGADOS ES-

PECIALIZADO EN

MATERIA PENAL 
dotarlo del soporte metodológico educativo —que nuestra alma mater sí se viene otorgando- y evaluar qué perfil de abogado representa en la sociedad, de tal forma que los «doctores Chantada» o los «académicos» corruptos puedan ser identificados y ubicados en el ámbito social que les corresponde, para permitir que las universidades cumplan con el rol de brindar formación integral que la sociedad les demanda.

\section{LOS PROCURADORES}

No podemos olvidar a los ex secretarios y ex adscritos que se acercan a los estudios a ofrecer «servicios de procuraduría» y garantizan resultados sobre la base de su cercanía a operadores de justicia, al ser estos quienes en muchos casos se encargan del «trabajo sucio». Incluso existe una suerte de competencia entre diferentes procuradores que saben que, cuando se enfrentan a determinado estudio, deben llegar antes que el procurador de la contraparte para «ejercer sus influencias»o, de lo contrario, será muy tarde «para ser eficaces». Ojo con ellos.

\section{LOS PRACTICANTES}

Finalmente, se encuentran los practicantes: jóvenes que comienzan su formación e ingresan a algún estudio con la ilusión de acercarse al ejercicio profesional de la carrera, solo para descubrir — aquellos que logran descubrirlo- que el estudio y los escritos que tanto trabajo les cuestan son simplemente una fachada porque el resultado del caso ya está garantizado.

En este sentido, el esfuerzo de Ciudadanos al Día parece crucial respecto de dotar a los estudios de abogados de una normatividad ética, a lo que pueden aunarse actos concretos como suscribir y avalar, tras el análisis jurídico, casos escandalosos que concluyeron en sentencias condenatorias: por ejemplo, las ejemplares sentencias del caso del ex presidente Fujimori. A ver quiénes — abogados y estudios de abogados — firman y publicitan su respaldo.

\section{CONCLUSIÓN}

En el ámbito descrito, el pro bono ${ }^{10}$ encuentra una real ubicación. Sumergirnos solamente en el análisis de quién defiende casos gratuitos y

10 «El término latino 'pro bono publico', comúnmente acortado a 'pro bono', significa por bien público. El concepto de trabajo pro bono - asegurando acceso a la justicia a cualquier persona desprovisto de la posibilidad de pagar - se ha desarrollado a lo largo de los siglos y generalmente se traduce en abogados donando un porcentaje de su tiempo a personas de escasos recursos que de otra manera no tendrían acceso a una asistencia legal. Mucha gente utiliza el término pro bono incluyendo trabajo que tradicionalmente no es llamado trabajo pro bono. Uno de los objetivos de la Secretaría (Secretariat) es unificar una definición de pro bono público en Australia. La Secretariat ha adecuado sutilmente la definición del Law Council of Australia (Consejo Legal de Australia) para satisfacer nuestras necesidades, de la siguiente manera: 1 . Un abogado que no cobra honorarios o sin expectativa de remuneración o con una remuneración sustancialmente reducida, asesora o 
quién no muchas veces puede conducir a una visión equivocada. Si solamente se mira ese aspecto puntual, celebraremos que determinado estudio —o abogado — tiene varios o muchos casos pro bono, aunque solo sean para maquillar una imagen que contraría su responsabilidad social.

La pregunta fundamental es la siguiente: ¿aun así vale la pena que los estudios asuman la gratuidad de algunos casos puntuales, lo cual representaría una forma de conformarnos — aplicando la expresión «del lobo, un pelo»-? ¿O debemos revisar, bajo estándares más objetivos y amplios, el ejercicio profesional de cara a saber cuál es la práctica general de dichos estudios y si esta fomenta el fortalecimiento de instituciones como el Ministerio Público, el Poder Judicial y la propia Policía Nacional del Perú, o si más bien se aprovechan de sus carencias y presentan el pro bono como «una lavada de cara», con un presupuesto establecido para confundir a la ciudadanía y que esta no los tache ni difumine el humo que genera su «desenvolvimiento académico»?

Existe una gran responsabilidad académica de las universidades, no solamente para exigir un alto rendimiento académico por parte de sus profesores, sino cualidades y valores en su ejercicio profesional. Es decir, se debe verificar si estos en la práctica aplican una pantalla académica para alcanzar el puro y mero lucro patrimonial.

Entonces, creemos que los casos pro bono configuran un peldaño de todos los que conforman la escalera de la responsabilidad social del abogado. Queda como responsabilidad del Estado proporcionar y exigir a las universidades una educación solvente, tanto en el aspecto académico cuánto ético, que permita que, cuando los estudiantes salgan al mercado, puedan ser profesionales que se desempeñen de manera transparente y, cuando incursionen en las instituciones públicas, mantengan su integridad solidificando las instituciones para impartir una real justicia social.

En cuanto a los estudios de abogados, en lugar de limitarse a crear un programa genérico que pueda ser utilizado como declaración o compromiso de respetar ciertos valores, sería mejor elegir un caso simbólico de corrupción, analizarlo jurídicamente y suscribir la respectiva condena. No solo el caso del ex presidente condenado por delitos de lesa humanidad, sino también el caso del general Chacón — como aparentemente lo está solicitando- podrían ser materia de análisis. Sería bueno que los constitucionalistas, los penalistas, los procesalistas se reúnan y tracen una línea. Dicha discusión, y la firma de un documento, beneficiaría sin duda a estudiantes, abogados y ciudadanos en general, y jueces y fiscales

representa a un cliente en casos donde: (i) el cliente no tiene otra forma de acceder a los tribunales y el sistema legal o su acceso es inadecuado; y/ o (ii) el caso del cliente reviste un carácter amplio de interés público: o; 2. el abogado está involucrado en educación legal comunitaria gratuita y/ o reforma legal; o 3. el abogado está involucrado en dar asistencia legal gratuita y/ o representar a entidades caritativas u organismos comunitarios». Colegio de Abogados de la Ciudad de Buenos Aires. En $<$ http://www.probono.org.ar/nota.php?id=21>.

RESPONSABILI-

DAD SOCIAL DE UN ESTUDIO DE ABOGADOS ESPECIALIZADO EN MATERIA PENAL 
sabrían que la discusión académica se halla detrás de su actuación jurisdiccional. Así, no nos limitaremos al trillado discurso de que «hay que luchar contra la corrupción», sino que habremos dado un nuevo paso en una lucha efectiva.

En conclusión, el pro bono nos obliga a ampliar la mirada, a desarrollar el radio de acción de la responsabilidad social del abogado, sin limitarnos a la asunción de casos sociales, sino a aplicar dicha línea principista —en el plano académico, en el plano del ejercicio profesional, en el plano institucional interno del estudio al que se pertenece- a todos los ámbitos del ejercicio profesional del Derecho. 